\title{
Erratum
}

\section{Cardiovascular Risk Factors Characteristic for the Metabolic Syndrome in Adult Patients with} Type 1 Diabetes

J. Nádas ${ }^{1}$, Z. Putz ${ }^{1}$, J. Fövényi ${ }^{2}$, Z. Gaál ${ }^{3}$, A. Gyimesi ${ }^{4}$, T. Hídvégi ${ }^{5}$, N. Hosszúfalusi ${ }^{6}$, G. Neuwirth ${ }^{7}$, T. Oroszlán ${ }^{8}$, P. Pánczél ${ }^{6}$, G. Széles ${ }^{9}$, G. Vándorfi ${ }^{10}$, G. Winkler ${ }^{11}$, I. Wittmann ${ }^{12}$, G. Jermendy ${ }^{1}$

\footnotetext{
${ }^{1}$ Bajcsy-Zsilinszky Hospital, Budapest

${ }^{2}$ Péterfy Hospital, Budapest

${ }^{3}$ Jósa Hospital, Nyíregyháza

${ }^{4}$ Réthy Hospital, Békéscsaba

${ }^{5}$ Petz Hospital, Gyõr

${ }^{6}$ Semmelweis Medical University, Budapest

${ }^{7}$ Kenézy Hospital, Debrecen

${ }^{8}$ County Hospital, Zalagereszeg

${ }^{9}$ Medical University, Debrecen

${ }^{10}$ Cholnoky Hospital, Veszprém

${ }^{11}$ Szent János Hospital, Budapest

${ }^{12}$ Medical University, Pécs, Hungary
}

Please note: in this article several spelling mistakes were corrected after e-first online publication. DOI 10.1055/s-0028-1082068

Published online: August 26, 2008

Exp Clin Endocrinol Diabetes 2009; 117: 107-112 